\title{
Factors underlying diagnostic delay in tuberculosis patients in a rural area in Tanzania: a qualitative approach
}

\author{
L. M. Verhagen $\cdot$ R. Kapinga • \\ K. A. W. L. van Rosmalen-Nooijens
}

Received: 5 May 2010/Accepted: 30 August 2010/Published online: 29 September 2010

(C) The Author(s) 2010. This article is published with open access at Springerlink.com

\begin{abstract}
Background Diagnostic delay in patients with tuberculosis (TB) leads to ongoing TB transmission, higher mortality rates and increased patient and government health expenditure. Qualitative research focussed on patients' self-perceptions of disease and their care-seeking behaviour helps to guide health education programmes by providing us with the understanding of the knowledge, attitudes and practices that underlie diagnostic delay.

Patients and methods Semi-structured interviews with 28 recently diagnosed TB patients and four traditional healers were conducted. The interviews were audio-recorded and content analysis was performed.

Results The median total delay was 188 days. The health provider delay ( 31 days) was longer than the patient delay (21 days) and the health system delay (26 days). The health system delay was longest in patients not being diagnosed at their first hospital visit and subsequently visiting other health care providers, mostly traditional healers.
\end{abstract}

L. M. Verhagen ( $₫)$

Division of Pediatric Infectious Diseases,

Department of Pediatrics, Radboud University Nijmegen

Medical Center, P.O. Box 9101, 6500 HB Nijmegen,

The Netherlands

e-mail: lillyverhagen@hotmail.com

R. Kapinga

Sumve District Designated Hospital,

P.O. Box 23, Mantare via Mwanza, Tanzania

K. A. W. L. van Rosmalen-Nooijens

Department of Primary and Community Care,

Unit Women's Studies Medicine, Radboud University Nijmegen

Medical Center, P.O. Box 9101, 6500 HB Nijmegen,

The Netherlands

e-mail: k.vanrosmalen@elg.umcn.nl
Conclusions A poor knowledge of TB signs and symptoms and patients' beliefs about curses as the origin of diseases lead to delayed care-seeking at the hospital level in an area of North-Western Tanzania. Failure to identify TB cases by formal and non-formal health providers indicates that the education of both communities as well as health workers is essential in order to reduce diagnostic delays.

Keywords Tuberculosis - Patient delay ·

Health provider delay · Diagnostic delay · Tanzania .

Traditional healer

\section{Introduction}

Tuberculosis (TB) is still a leading cause of death in lowincome and middle-income countries, especially those of sub-Saharan Africa, where TB is an epidemic because of the increased susceptibility by human immunodeficiency virus (HIV) infection. The most recent World Health Organization (WHO) estimates of the worldwide TB epidemic are for 2007, when there were 9.27 million new cases, equal to an incidence of 139 per 100,000 population. The United Republic of Tanzania is among the countries with the highest TB burden, with a TB incidence of $297 / 100,000$ in 2007. The WHO statistics from Tanzania show an alarmingly low case detection rate: from 2001 to 2007, the percentage of new TB cases detected by the National Tuberculosis and Leprosy Program (NTLP) has been stable and around 47\%, which is well below the target of 70\% [1]. Case-finding in Tanzania is passive, and TB control is integrated into the general health system, depending on the patients themselves to present to health services when they suspect TB. Delay occurs when a patient fails to recognise symptoms due to a lack of knowledge or when they do not have the confidence that the health 
service will provide adequate service, both of which have been described in the literature [2,3]. Besides these patientrelated factors, misdiagnosis at the health facility level can also significantly increase diagnostic delay [4]. The subsequent delayed initiation of treatment causes spread of infection in the community, increases patient expenditure and is associated with a higher risk of mortality [5].

Distributions of diagnostic delays tend to be skewed: they are relatively short for most TB patients but very long for some [6-8]. Patients with long diagnostic delays may thus, contribute, disproportionately to the cumulative delay of all patients. Prevention of these long delays could, therefore, be more effective in curbing TB transmission than further reduction of the median delay among all patients. It is, thus, important to know the risk profile of patients with long diagnostic delays. Qualitative research directed at increasing our knowledge of the factors affecting delay plays an important role in this matter. In a recently published systematic review of the literature, Tanzania was reported as the country with the longest total delay in the diagnosis of TB [9]. We performed series of in-depth interviews to gain insight into the factors underlying treatment-seeking behavioural patterns in TB patients in Sumve, Mwanza region, Tanzania. We paid special attention to the role of different health care providers. Since Wandwalo and Mørkve in an earlier study from the Mwanza region identified traditional healer visits as a source of delay [10], we specifically focussed on these care providers and also paid attention to their perspective by performing in-depth interviews with four traditional healers in our study area.

\section{Patients and methods}

We performed a qualitative survey [11] exploring the knowledge, attitudes and practices of TB patients.

Study area

The study was conducted in Sumve designated district hospital (DDH) in Kwimba district in the Mwanza region, North-Western Tanzania. The Mwanza region has a population of about 2.5 million people and comprises seven districts. The major ethnic group $(>90 \%)$ in the area is the Wasukuma. Kwimba district has almost 400,000 inhabitants and two district hospitals: one governmental hospital in Ngudu and one mission hospital in Sumve, where our research was performed. There are no general practitioners or private facilities in Kwimba district. Basic formal health care is provided by the 31 dispensaries. These services are generally not equipped with TB diagnostic facilities; the diagnosis and management of TB is exclusively provided by hospitals. Outreach activities performed by the staff of
Sumve DDH are public health meetings in schools, eye mobile services, mosquito netting projects and water well development. Each village in Kwimba district is visited 2-3 times a year by an outreach team, including one representative of each project. In Sumve DDH, 120 new TB cases were diagnosed in 2007.

Population

The target group consisted of patients diagnosed with TB in Sumve DDH in the period September-November 2008. Both in- and out-patients were included in the study, regardless of the sputum result, type of TB or HIV status. Patients with TB relapses after complete TB treatment in the past were excluded. The patients were approached by the TB nurse of the hospital and informed about the research. If patients were interested, general characteristics, such as sex, age, occupation, education, marital status, distance to the hospital, children, religion, tobacco use and alcohol usage, were recorded. We started to interview the first 15 patients who were willing to participate. Later on, the patients were chosen based on the characteristics mentioned above to make the sample as varied as possible.

\section{Data collection}

The research consisted of patient interviews lasting 45-60 min. The interviews were carried out in the hospital by one of the authors and the TB nurse. All interviews were undertaken face-to-face; at each interview, only the participant, one of the authors and the TB nurse were present. Interviews were held in Kiswahili, the national language, spoken by one of the authors and the TB nurse. An interview guide was used for each interview. To compose the interview guide, we performed an electronic search using the TRIP database, Cochrane Library and PubMed with the key words 'tuberculosis', 'delay', 'knowledge' and 'health seeking behaviour' in various combinations. Additional studies were identified by searching the reference lists from existing articles. The interview guide contained questions about symptoms, health-seeking behaviour, reasons for delay, treatment given, knowledge about the causes and treatment of TB, sources of information, emotional aspects and care for children. Most questions were open-ended, but some were multiple-choice. After two test interviews, the interview guide was slightly modified. These two test interviews were not included in the data analysis. The interview guide was narrowed down in the course of the research, focussing on major themes arising during content analysis [11]. The entire interview was recorded on tape. Each interview was typed out ad verbatim and translated into English. Both the TB nurse and one of the authors translated every interview together in order to be sure of a 
correct translation. To guarantee the anonymity of the participants, all names and references were removed from the files, and each interview was given a number.

\section{Definitions}

Mycobacterial culture facilities and drug susceptibility testing are not available at Sumve DDH. Pulmonary TB diagnosis was based on the standard procedures recommended by the National TB Control Programme, which recommends to examine three sputum specimens from selfpresenting symptomatic patients on two consecutive days [12]. Smear-positive pulmonary TB is confirmed when there are at least two acid-fast bacilli (AFB)-positive smear results or when one sputum specimen is positive for AFB in addition to radiographic abnormalities consistent with active pulmonary TB. Smear-negative pulmonary TB is diagnosed in a patient with three smear examinations negative for AFB with clinical and radiographic abnormalities consistent with active TB not responding to a course of broad-spectrum antibiotics [12]. As bone biopsy was not routinely performed in Sumve DDH, osteal TB was defined as clinical and radiographic findings consistent with osteal TB. X-rays were interpreted by two experienced independent radiologists who reported pleural or parenchymal pathology, as well as pulmonary, hilar or mediastinal calcifications on chest X-rays and radiologic abnormalities on bone X-rays.

Figure 1 provides an overview of the delay definitions used in this research. Patient delay was defined as the duration in days from the reported onset of symptoms to the first visit to a health provider. Health provider delay was defined as the duration in days between the first visit to a health provider and the first visit to the hospital. Health providers were broadly defined as any person consulted by the patient about his/her sickness that gave or prescribed something (whatever the form) for treatment. Health system delay was defined as the duration in days between the first presentation at a hospital until the start of anti-TB treatment. Health system delay was further divided into diagnostic delay, the time interval from the first presentation at the hospital to TB diagnosis, and treatment delay, the time interval from TB diagnosis to the initiation of antiTB treatment. The total delay was defined as the duration in days between the reported onset of symptoms and the start of anti-TB treatment.

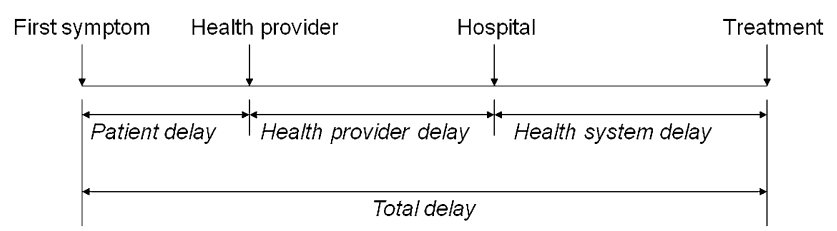

Fig. 1 Definitions used in this research
Data analysis

The interviews were analysed directly after the interview. An inductive content analysis was performed, meaning that interviews were reviewed and coded for unifying ideas which were grouped into themes and sub-themes that emerged from the interviews [11]. Each interview was coded by two researchers using the qualitative data analysis software MAXQDA (VERBI Software, Berlin, Germany). The two researchers then read coded segments together in order to reach a consensus about the applied codes. When more data became available, these were compared to the codes, themes and sub-themes already formulated and, if necessary, adjustments were made. After 15 interviews, one of the main themes emerging from the analysis was delay due to regular visits to alternative health providers. Therefore, the remaining interviews focussed on this theme and the first interviews were analysed again, focussing on this theme. After 28 interviews, no new information arose within this theme, reaching theoretical saturation.

Quotes have been selected to illustrate the themes and have been translated into English. The quotes of TB patients are followed by name (pseudonym), age, sex and type of TB to give the reader more insight into the diversity of the patients who participated.

Chi-square tests were performed to compare delay duration in smear-positive and smear-negative TB cases. The SPSS package for Windows version 16.0 (SPSS Inc., Chicago, IL, USA) was used for these analyses. The reported $p$ values are two-sided.

\section{Traditional healers}

Interviews were carried out with four traditional healers living in Kwimba district, the district where the majority of our patients $(63 \%)$ resided. The methods described above also applied for the interviews conducted with the traditional healers. The interview guide for the traditional healers was composed of questions arising from the second analysis of the patient interviews and were modified after consulting the Public Health Coordinator of the hospital. The interview guide contained questions concerning thoughts about cough and TB, the origin and treatment of diseases, and the referral of patients.

The quotes of the traditional healers are followed by name (pseudonym) and the year which the traditional healer started working.

Ethical considerations

The board of Sumve DDH approved this research. Because most patients were illiterate, informed consent was obtained verbally from all patients and recorded on tape. 
Table 1 Characteristics of the study population a The clinical WHO stage of all HIV-positive patients was

stage 3

b Religion 'none' was defined as no worship of a God or Gods. Belief in bewitchment was not considered as having a religion

c Smoking was defined as the inhaling of any kind of lighted pipe, cigar, cigarette or any other lighted smoking equipment containing any burning substance or product, including tobacco, that is intended for human consumption by means of inhaling the smoke therefrom

d Alcohol use is defined as drinking at least two alcoholic beverages daily

\begin{tabular}{l}
\hline Sex \\
Male \\
Female \\
\\
Age (mean 46.1 , median 43.5 , range $18-80$ years) \\
$\quad<45$ \\
$\geq 45$
\end{tabular}

Occupation

Farmer

Student

Priest

Education

No education

Primary school, not completed

Completed primary school

Secondary school, not completed

Completed secondary school

Marital status

Unmarried

Married

Widowed

Divorced

HIV

Negative

Positive $^{\mathrm{a}}$

CD4 0-100

CD4 100-200

CD4 200-300

CD4 300-500

CD4 $>500$

1
Distance to hospital

$<5 \mathrm{~km}$ 5

$5-10 \mathrm{~km}$

$>10 \mathrm{~km}$

Children

0

$1-5$

$>5$

Religion

$\begin{array}{ll}\text { Christian } & 19\end{array}$

Muslim 1

None ${ }^{\text {b }}$

Smoking ${ }^{\mathrm{c}}$

Yes

Stopped because of symptoms 4

No

0

Alcohol $^{\mathrm{d}}$

Yes 5

Stopped because of complaints 2

No

Type of TB

Smear-positive pulmonary TB $\quad 14$

Smear-negative pulmonary TB $\quad 12$

Osteal TB

Spinal TB
Patients were reassured of the confidential handling of the research data.

\section{Results}

Characteristics of the study population

Of the 30 approached patients, 28 (93\%), 18 males and ten females, took part in this research. Two patients did not participate because they suffered from clinical deterioration on the day that the interview was planned. Both patients had already agreed to participation and the clinical deterioration took place after the agreement. Characteristics of the study population are shown in Table 1 and an overview of the signs and symptoms of all patients is given in Table 2.
Factors associated with delay

The median total delay was 188 days (mean 289, range 32-1,146). A longer median total delay was noted in men compared to in women (213 days vs. 126, respectively) and patients aged less than 45 years (300 days vs. 126 days in patients aged 45 years and over). Furthermore, widowed or divorced patients, patients who lived more than $10 \mathrm{~km}$ from the hospital, patients not having a religion, patients consuming alcohol and patients who stopped smoking because of their symptoms reported a longer total delay. The median total delay became shorter as the educational level was higher. Illiterate people showed the longest delays. Table 3 provides information on the delay periods for each patient to allow case-attributed estimations.

The median total delay in the two episodes of osteal TB was 577 days and the median total delay in pulmonary TB 


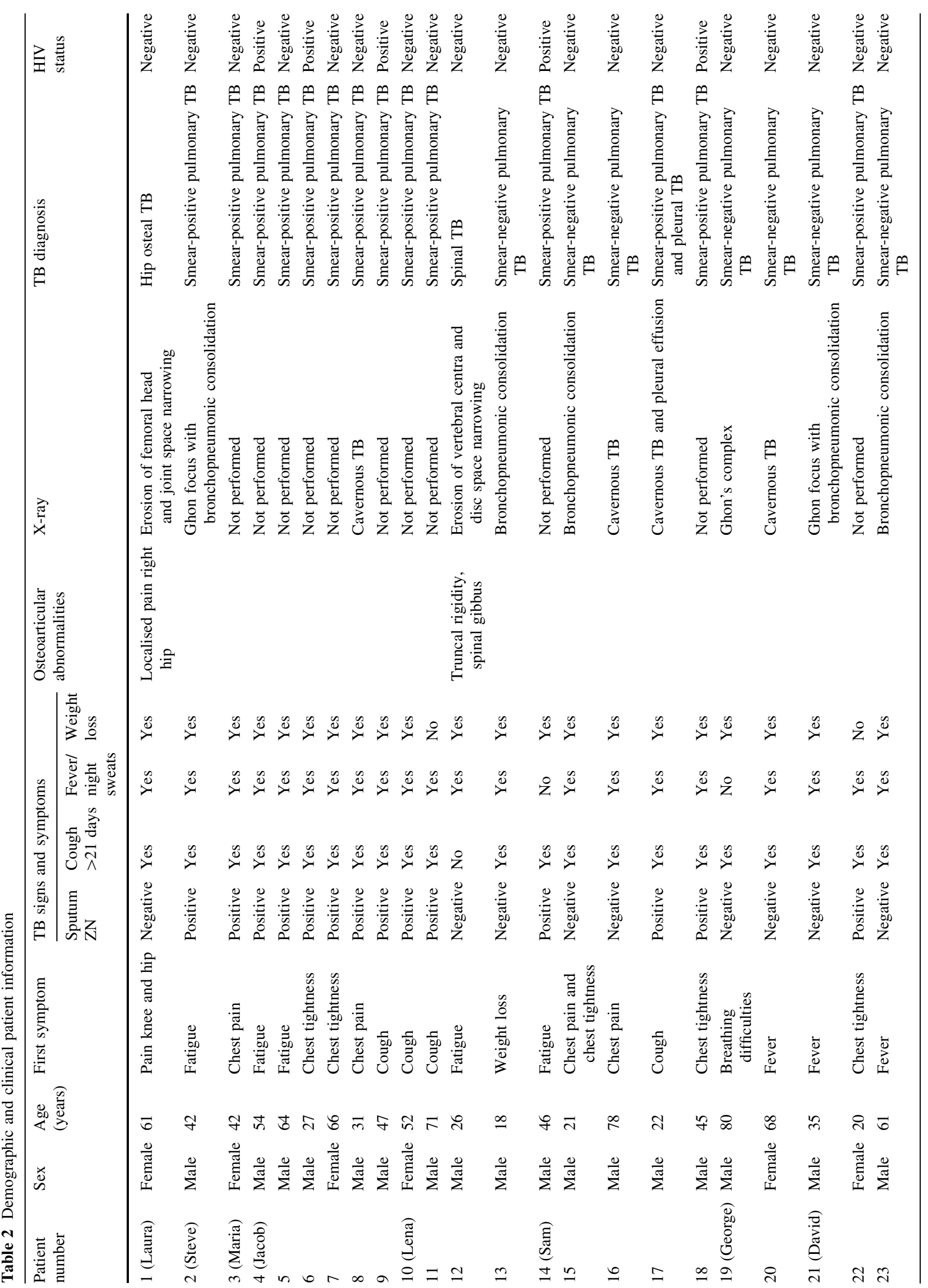




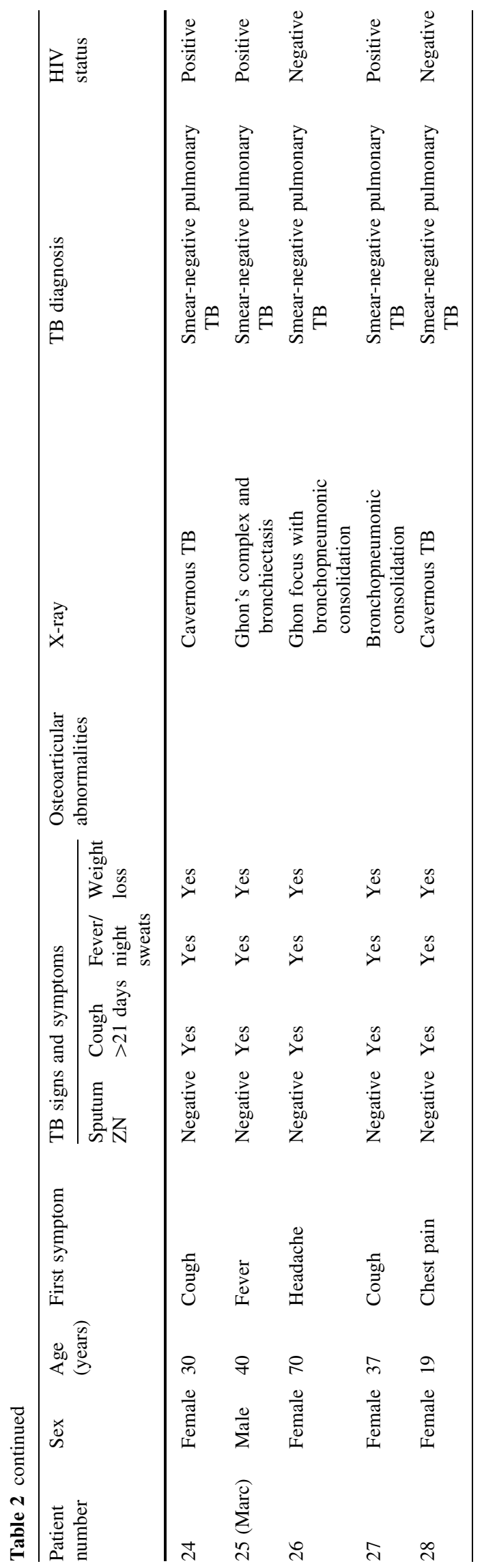

patients was 169 days. While the median patient delay in the osteal TB episodes was only 11 days (compared to 26 days in the pulmonary TB episodes), both the median health provider delay and the health system delay were strikingly long, 302 days and 265 days, respectively. Table 4 shows that no significant difference in delay durations was noted between smear-negative and smearpositive cases. A trend towards a longer patient delay and a shorter provider delay in smear-positive cases $(p=0.07$ and $p=0.05$, respectively) was seen.

Patient and provider delay and care-seeking

The median patient delay was 21 days (mean 85, range $0-546)$. For the majority of patients, the traditional healer was the first health provider visited. The median health provider delay, the time from the first visit to traditional healer, pharmacy or dispensary until the first hospital visit, was 31 days (mean 92, range $0-732$ ).

Most patients visited several places before being diagnosed at the hospital. Seventeen patients went to a traditional healer. A pharmacy was visited by 16 patients and nine visited a dispensary. If visited, these places were generally visited more than once (Table 3 ).

\section{Reasons to delay a hospital visit}

The majority of patients visited a health provider within a month of the onset of signs and symptoms, while only five patients went to a hospital within a month (Table 3). Seemingly strange, all patients said they had known that $\mathrm{TB}$ is a disease that requires hospital treatment and $40 \%$ even said this was the only thing they had known about TB before being diagnosed. Among the $60 \%$ of patients that had some knowledge of TB, coughing was the symptom most often mentioned as characteristic for TB. Other chestrelated symptoms such as chest tightness and/or chest pain were also frequently mentioned. Only four patients mentioned weakness and/or weight loss, and fever was not mentioned at all.

Before I got TB, I knew nothing about this illness. People from my village just mention TB as a disease that should be treated by hospital medication. They say that when you have TB, you should not go to the traditional healer. Anything else about TB, its causes and symptoms, they do not say. (David, 35-year-old male, sputum-smear-negative pulmonary TB)

All patients could sum up several acquired immune deficiency syndrome (AIDS)-related symptoms, the most frequently reported were weight loss, weakness, diarrhoea, oral thrush and fever. Fear of being diagnosed with AIDS 


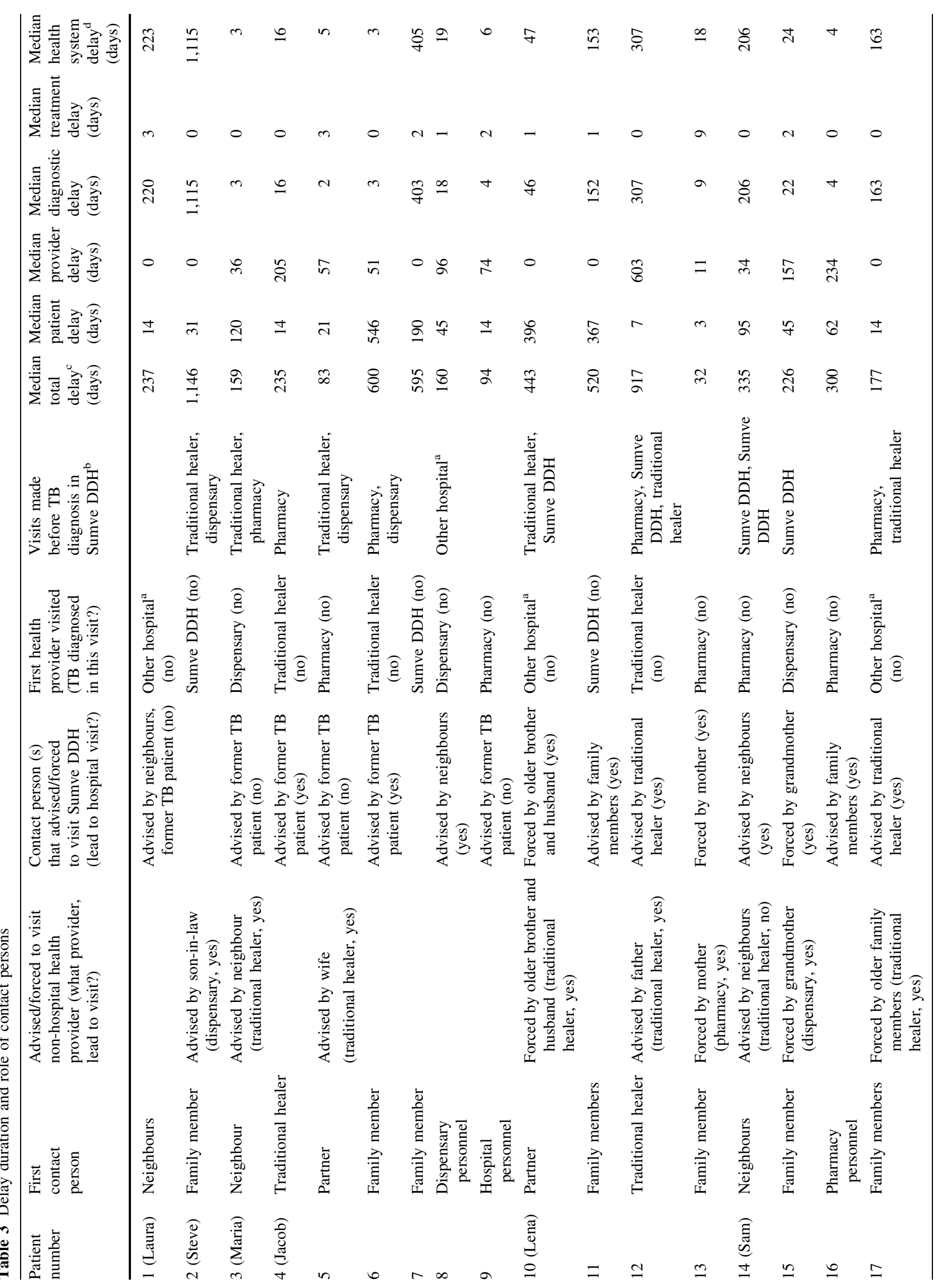




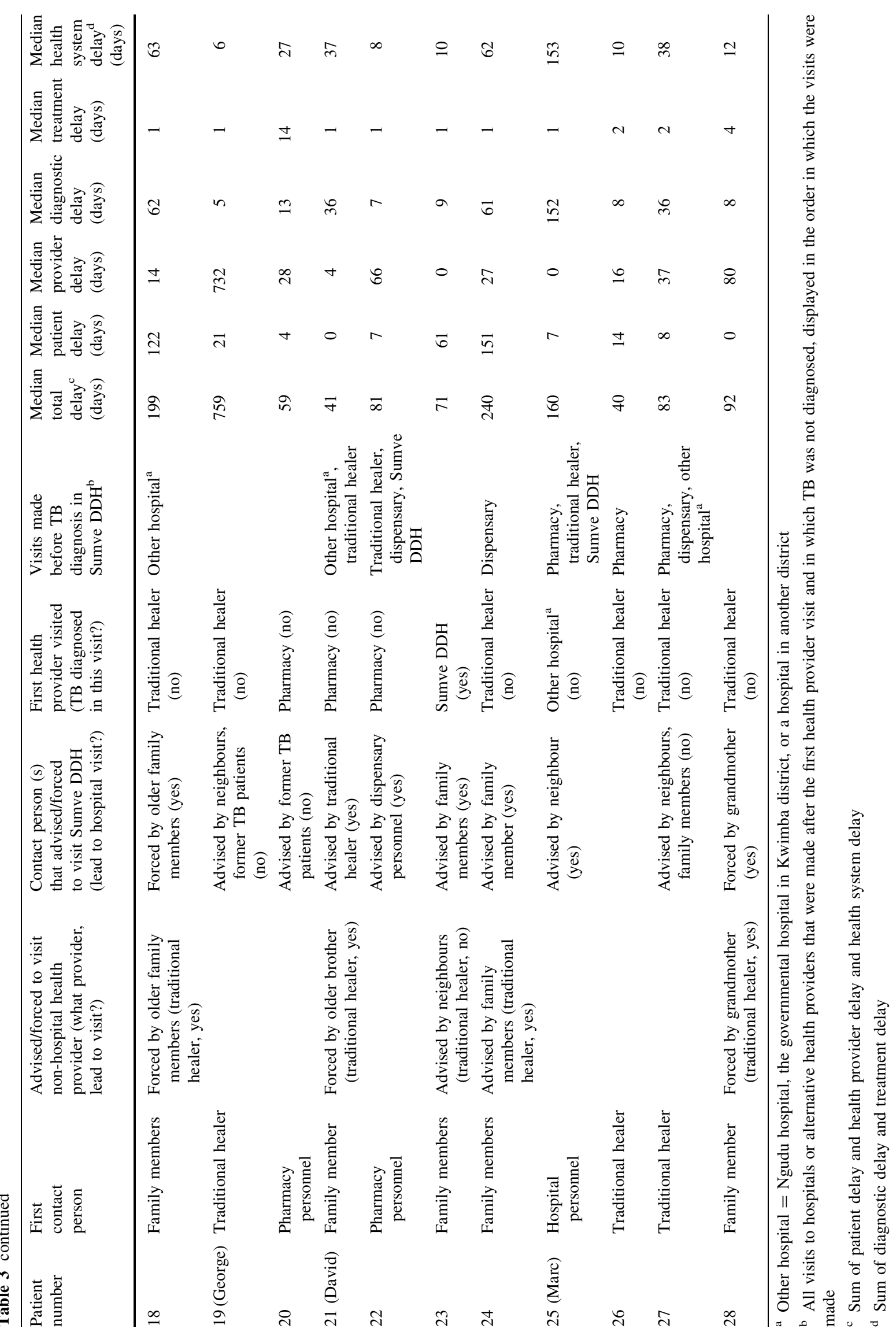


Table 4 Delay in smear-positive and smear-negative tuberculosis (TB) cases

\begin{tabular}{|c|c|c|c|}
\hline & $\begin{array}{l}\text { Smear- } \\
\text { negative }\end{array}$ & $\begin{array}{l}\text { Smear- } \\
\text { positive }\end{array}$ & $p$ value \\
\hline Sex & & & 0.43 \\
\hline Female & 6 & 4 & \\
\hline Male & 8 & 10 & \\
\hline Patient delay in days & & & 0.07 \\
\hline 1st quartile $(<8)$ & 6 & 1 & \\
\hline 2nd quartile (8-20) & 3 & 3 & \\
\hline 3rd quartile (21-113) & 4 & 4 & \\
\hline 4th quartile $(>113)$ & 1 & 6 & \\
\hline Provider delay in days & & & 0.05 \\
\hline 1st quartile $(<1)$ & 3 & 5 & \\
\hline 2nd quartile (1-30) & 5 & 1 & \\
\hline 3rd quartile (31-78) & 1 & 6 & \\
\hline 4th quartile $(>78)$ & 5 & 2 & \\
\hline Health system delay in days & & & 0.29 \\
\hline 1st quartile $(<9)$ & 2 & 5 & \\
\hline 2nd quartile (9-25) & 5 & 2 & \\
\hline 3rd quartile (26-152) & 4 & 2 & \\
\hline 4th quartile $(>152)$ & 3 & 5 & \\
\hline Total delay in days & & & 0.20 \\
\hline 1st quartile $(<9)$ & 5 & 1 & \\
\hline 2nd quartile (9-25) & 3 & 5 & \\
\hline 3rd quartile (26-152) & 4 & 3 & \\
\hline 4th quartile $(>152)$ & 2 & 5 & \\
\hline
\end{tabular}

was mentioned by several patients as a reason to delay care-seeking.

I just stayed home because I was afraid I was suffering from HIV. I was not coughing too much, my family hardly noticed it. As I got thinner, the fear that I was suffering from HIV became bigger, really, I was so afraid to be HIV-infected! I feared to get that result when coming to the hospital; however, the HIV test was negative. Apparently, the symptoms of these diseases are similar. (Lena, 52-year-old female, sputum-smear-positive pulmonary TB)

When patients were asked what had made them wait before seeking medical attention at the hospital level, most of them (19 patients) spontaneously replied they were initially not thinking of TB as a cause of their symptoms. Some patients said they initially thought that they were suffering from 'normal fever' or malaria, which had made them visit a pharmacy.

I got ALU (Artemether Lumefantrine) and acetaminophen at the dispensary [...] I went back again because 2 weeks after finishing the ALU and acetaminophen, I kept on coughing and feeling chest pain; there, I was prescribed ALU and acetaminophen again. The second course of ALU did not improve anything either, so I returned to the dispensary for the third time, just to get $A L U$ and acetaminophen again. (Maria, 42-year-old female, sputum-smearpositive pulmonary TB)

The patients that had visited a traditional healer before going to the hospital said they had approached a traditional healer because they were ascribing their symptoms to sorcery (kurogwa) or witchcraft (uchawi). The general idea expressed by all patients was that either God, or Allah in one case, or witchcraft can give diseases to humans. While diseases given by God should be treated in a hospital, witchcraft curses require treatment from a traditional healer.

When they investigate you in a hospital and the disease appears, it is a punishment of God. My disease appeared here in the hospital, so it is a disease given by God. However, if your disease does not appear when you are investigated in the hospital, the reason must be that you are cursed; that it is a witchcraft disease. (Jacob, 54-year-old male, sputum-smearpositive pulmonary TB)

All but two patients perceived their disease as a punishment. The patients that had visited a traditional healer said they had thought they were punished by witches, which was why they approached a traditional healer. While 'the witch' was, for most patients, an unknown entity, some thought they had been cursed by acquaintances. The oldest sister of the father of the patient was mentioned several times as somebody having witchcraft powers. Most patients said witches randomly choose people to put a spell on, but two patients explicitly mentioned that relationship problems are often a reason for being cursed.

The traditional healer confirmed my suspicions that somebody had put an evil spell on me. Me and my first wife, we had seven children. My second wife now wanted to punish me for the fact that I did not give her any children. (Steve, 42-year-old male, sputumsmear-positive pulmonary TB)

For all patients that had initially thought they were cursed, the fact that their disease was diagnosed in the hospital was perceived as a proof that TB is a punishment of God rather than caused by witchcraft forces.

Now I realise it has nothing to do with witchcraft, like I thought in the past. It is a punishment of God. He pushes the wind that contains $T B$ in the direction of the person that will subsequently develop TB. (Maria, 42-year-old female, sputum-smear-positive pulmonary TB) 
After being diagnosed with TB in Sumve DDH, all nonreligious patients said that God had probably punished them because they are not religious and do not go to church. The others did not know why they were being punished.

Financial considerations also played a role in careseeking behaviour. Although TB treatment is free of charge in Tanzania, this did not affect the care-seeking behaviour, as most patients did not ascribe their symptoms to TB. Furthermore, patients were aware of the fact that examinations such as chest X-rays do need to be paid. Not having enough money was mentioned by several patients as a reason to go to a traditional healer first, as they could be paid in kind with fowls, foodstuff and goats.

I wanted to go to the hospital, but I did not have the money, so I went to a traditional healer first as I could pay him with goats. After being treated by him for a long time, my children sold my cows to get money for the treatment in Sumve hospital. (George, 80-year-old male, sputum-smear-negative pulmonary TB)

Patients often had several reasons for postponing a visit to the hospital. In addition to the factors above, slow onset of symptoms and a long distance to the hospital were mentioned. When asked what had prompted patients to seek medical attention at the hospital, all patients cited non-resolving or worsening symptoms.

\section{Role of relatives and neighbours in care-seeking}

Table 3 includes information on the patients that were advised or forced by relatives, neighbours or health providers to seek care at certain places. Most patients were free to decide what health provider they approached first. Patients that were forced to visit certain health providers were generally younger people forced by older male or female family members. There does not seem to be a general pressure to visit a traditional healer before visiting the hospital, as, for most patients, the reason to visit a traditional healer was that they themselves thought they were cursed. The fact that two patients did not follow the advice of others to visit a traditional healer also indicates that patients are generally free to decide for themselves.

I felt a sharp chest pain, was coughing and suffered from fever. When the cough got worse, other people told me I might be suffering from a second tongue coming out of my throat and should visit a traditional healer. However, I did not really think this; I thought I just had a normal fever, just the fever you get sometimes and from which you recover with some medicine from the pharmacy. (Sam, 46-year-old male, sputum-smear-positive TB)

The first person the patient talks to in terms of complaints is, in the majority of cases, a family member. However, for a significant number of patients, the first person they tell about their complaints is a health provider.

Health system delay

The median health system delay was 26 days (mean 112, range $3-1,115)$. The median diagnostic delay was 20 days (mean 110, range $2-1,115)$, while the median treatment delay was only 1 day (mean 2, range 0-14).

The low median diagnostic delay of 20 days shows that a few cases are responsible for the high mean of 110 days. These are the cases in which a TB diagnosis was missed during a hospital visit. Half of the pulmonary TB patients made one or more hospital visits in which TB was not diagnosed. In only six visits, the advice to come back in case no improvement would be seen was given. The two cases of osteal TB made, respectively, three and one nondiagnosing hospital visits.

The first time I was prescribed chloramphenicol tablets for 2 weeks. Since the hip pain remained, I went back to the hospital 2 weeks later. I was given amoxicillin for 2 months and a pelvic X-ray was taken. They told me I might be having osteal TB but I did not get TB treatment [...] I went to the hospital for the third time. They told me to continue amoxicillin for 2 more weeks. (Laura, 61-year-old female, hip osteal TB)

Patients that visited a traditional healer after they had visited a hospital without being diagnosed with TB all said that the reason for going to a traditional healer was the thought of bewitchment rather than God as the cause of their symptoms.

When I did not get better with the hospital medication, I thought that not God but witchcraft forces were making me ill. When witches spread cursed water on the road and you are the first one walking on that road, you are bewitched. For these diseases, we go to the traditional healer. (Marc, 40-year-old male, sputum-smear-negative pulmonary TB)

Excluding the patients that went to a traditional healer after visiting the hospital, the mean health system delay would be only 60 days, which means an almost $50 \%$ reduction. This reflects the long time that patients stay with a traditional healer before returning to the hospital and the disproportionate impact of these outliers on the mean health system delay. 
Traditional healers

Four traditional healers, all men, were interviewed. Each of them mentioned cough as a symptom of TB. Two also mentioned breathing difficulties, although one of them added that this was only present in the rainy season. Weight loss, nocturnal sweating and lymph node swelling were all mentioned once. None of them mentioned fever. All traditional healers mentioned a varying range of other symptoms as well, such as hair getting thinner, pain in the feet or bones, skin getting darker, skin rashes, a diminishing amount of total body water and swollen feet.

In addition to TB, several other causes of a chronic cough were mentioned, all of which are treated by the traditional healers themselves. Besides pneumonia, asthma and cardiac problems, several syndromes that are not recognised in conventional medicine, such as a second tongue growing out of the throat, the uvula growing downwards, the sternum bending inwards and worms in the throat, were mentioned.

Patients with fast breathing or dirty sputum I send to the hospital. But then, when I see an ill person coughing, and he coughs until there is really no breath left so that he can not stay inside the house anymore but has to go outside to get breath again, that one, I know he's not suffering from TB. This is typically a cardiac disease. When this person coughs, it smells a lot. This I can treat, really, since this is not $T B$ but a cardiac problem. (John, traditional healer since 1989)

All traditional healers emphasised the existence of witchcraft and the fact that doctors cannot treat cursed patient because their drugs have no power over black magic or witchcraft. However, all four clearly stated that TB should be treated in the hospital. They said to refer patients in whom they think of a diagnosis of TB to the hospital.

\section{Discussion}

This study shows that TB patients in a rural area in Tanzania suffer from substantial delays until a diagnosis is made. The fact that, in our study, younger men showed a longer total delay is remarkable, since in a recently published systematic review, the main factors associated with delay included old age and female sex [13]. A possible explanation for this finding could be that almost all of our patients are farmers. In the Sukuma society, young men are responsible for the largest part of the work in the fields, while women are in charge of raising the children. This role pattern could lead to delayed care-seeking in young men because of the fear that the work in the fields is not done. HIV infection, low educational level, self-treatment, alcoholism and geographical barriers to health care were also associated with longer delays and these results do correlate with our findings. The reason that HIV-infected patients show longer delays may be that they already suspect they are suffering from HIV and fear to become stigmatised when their HIV status is revealed in the hospital. Stigma has a significantly negative and constant impact upon life satisfaction in HIV patients in Tanzania [14]. Sputum-smear-positive patients showed a trend towards a longer patient delay and a longer total delay. This finding is worrisome, as the spread of TB disease is mainly caused by patients with sputum-smear-positive TB $[15,16]$. However, in larger studies in sub-Saharan Africa, significantly longer delays were found in patients with sputum-smear-negative TB [13, 17]. A trend towards a longer patient delay in smear-positive patients was also reported in Nepal [18] and might be related to HIV stigma. Smear-positive patients may have more severe symptoms, leading to fear of stigmatisation because of the confusion of TB and AIDS symptoms, which has shown to deter patients from seeking early treatment [19]. This idea is supported by the finding that all of our participants said they recognised AIDS symptoms, while only 60\% were familiar with TB signs and symptoms. Especially, systemic symptoms are often linked to AIDS rather than to TB. Persons with a low knowledge of TB symptomatology may suspect that they have AIDS and, thus, delay care-seeking for what may actually be a case of TB. Confusion of TB and AIDS symptoms was also seen in central Tanzania, where focus group discussions revealed this theme [20]. All of our patients were aware that TB needed to be treated at a hospital, which is similar to studies from other parts of Tanzania [21, 22]. However, the majority of our patients were not attributing their symptoms to $\mathrm{TB}$, suggesting that their knowledge of this disease was not being personalised, which has been described in northern Tanzania as well [22]. The fact that almost half of the patients that were advised to visit a hospital initially did not follow this advice is probably also related to a poor perception about TB. As long as patients' awareness of TB signs and symptoms is low, they do not ascribe their complaints to TB and they do not visit a hospital, as there are other reasons preventing them from going there, such as financial considerations, geographical distance and the fear of being diagnosed with HIV. Interestingly, when dispensary personnel or traditional healers gave the advice to visit a hospital, their advices were followed, which is an indication of the faith which patients have in these health providers. Attention should, thus, be paid to the education of alternative health providers, especially because alternative health providers are often the first person to whom patients 
talk about their symptoms, with the objective of earlier referral of TB patients from alternative health providers to the hospital.

Although there were only two episodes of osteal TB in our study sample, their extreme long delay might reflect a lack of awareness of other types of TB among both hospital workers and other health care providers. Studies from developing countries that include extrapulmonary TB patients are scarce. In a recent study from Rwanda, a longer health system delay was significantly associated with extrapulmonary TB [23]. It is recommended to increase awareness on the extrapulmonary forms of TB among hospital workers, especially in the light of the rising percentage of HIV-infected people, as extrapulmonary presentation is more common in these patients [24, 25].

\section{Health provider delay}

The median health provider delay in our sample was longer than the median patient delay and the median health system delay. In Gambia and Ethiopia, where alternative providers also play an important role, studies using similar definitions for patient and provider delay were performed [7, 26]. Health provider delay in Gambia was also longer than patient delay, while in Ethiopia, an equal contribution of patients and non-formal providers to the delay before attending a medical facility was reported.

Alternative health providers visited in our study included pharmacies and dispensaries. A first visit to a drug store is common in developing countries and has been reported to be a source of delay. Only very few drug store visitors are advised to see a doctor [27-29]. A dispensary service is the first formal health unit of level one health services in Tanzania. While one-third of our patients visited a dispensary, only one of them was referred to a hospital by dispensary personnel. As we did not ask patients specifically whether they were referred to Sumve DDH but inquired about referral advices in general, it is unlikely that patients were referred to hospitals other than Sumve hospital by dispensary personnel. More likely, patients are not being advised to seek medical attendance at a higher level, despite showing no response to repeated courses of non-specific antibiotics, which is in concurrence with other sub-Saharan African studies on delay in TB patients, including primary health facilities [29-31]. In Kwimba district, dispensaries are not equipped with microscopes to perform sputum-smear microscopies. If TB detection rates are to be increased, low-level health facilities have to be formally involved in TB diagnosis and a combination of the education of dispensary personnel about TB signs and symptoms and training in the performance of smear microscopy is warranted.
One-third of our patients first visited a traditional healer after the onset of symptoms, making this the place preferred as the first point of call by most patients. Patients tended to stay with the traditional healer for a long time. This result is similar to a large cross-sectional study performed in 1998 in the Mwanza region, where also one-third of the study population visited a traditional healer first [10]. The majority of those who first presented to a traditional healer lived in a rural area. The median delay in patients first visiting a traditional healer was almost three times as long as the delay in those first consulting a conventional health facility. A longer delay in those initially visiting a traditional healer is also seen in studies from rural areas in other developing countries [7, 26, 32, 33]. In Dar es Salaam, the capital city of Tanzania, the median delay to visiting a health facility was only one and a half months and only $3 \%$ of 69 TB patients went to traditional practitioners as their first action [21], suggesting a relation between rural residence and the tendency to visit traditional healers.

Beliefs concerning the cause of the ailment was identified as an important determinant of initial health-seeking behaviour. Patients believed that diseases are caused by either God or witchcraft curses. While a previous study from central Tanzania only reported bewitchment as a perceived TB cause and God's will was not brought up as a cause of diseases [20], Ethiopian TB patients mentioned God, Satan and supernatural forces as potential senders of diseases [34]. In Ethiopia, these beliefs were not directly related to care-seeking behaviour, whereas in our study, the traditional healer was perceived as the only health provider having power over witchcraft forces. The earlier Tanzanian study also reported a link between the assumptions of witchcraft causes and traditional healer visits [20]. This indicates an urgent need to focus education in communities on symptoms and signs of $\mathrm{TB}$ and teach people how to recognise these, as this might lead to the perception of TB as a non-witchcraft disease and subsequent care-seeking at the hospital level. These educational activities should also involve health providers, including the personnel of pharmacies and dispensaries, and traditional healers. Very few patients were referred to the hospital by other health providers, a finding which is consistent with other studies in sub-Saharan Africa [7, 26, 33, 35]. Strikingly, all of the traditional healers which we interviewed stressed that they would refer a patient to the hospital as soon as they suspect TB, unlike traditional healers from Malawi and Rwanda, who claimed they could cure TB or certain types of TB [36, 37]. This discrepancy is likely to be the result of poor knowledge on TB signs and symptoms among traditional healers. Although all of them mentioned cough as a symptom of TB, a wide variety of other non-TB symptoms were mentioned and the awareness of systemic symptoms such as weight loss, night sweats and fever was low. 
Furthermore, a lot of different diseases and anatomical defects that can cause cough, and can be treated by the traditional healers themselves, were described.

Health system delay

Health system delays were mainly due to diagnostic delays. Patients often had several contacts with a formal health service before being diagnosed. Meanwhile, the traditional healer was the health provider most consulted because of the belief that, if conventional doctors were unable to solve the problem, witchcraft forces must be causing the disease. Traditional healer consultation after not being diagnosed in a hospital was also seen in Ghana, Botswana and South Africa [31, 33, 38]. Among participants in focus group discussions in Kenya, the use of traditional healers was seen as a valid alternative when the modern health services had failed [39]. In Botswana, 95\% of 212 patients included in a survey of pulmonary TB patients visited a medical facility first. However, the traditional healer was often visited after not being diagnosed and even after having started treatment with conventional TB drugs. The strong belief in traditional healers' treatment was related to the idea that either witchcraft or poisonous substances had caused the disease [40].

Beliefs about witchcraft among both traditional healers and patients seem to be deeply ingrained and may be confirmed by hospitals failing to make an adequate diagnosis at the first visit. Treatment by a traditional healer may, once started, take considerable time, and the patient may delay repeat visits to the health facility, increasing both health system delay and total delay. There seems to be a lack of awareness of TB among hospital staff, leading to misdiagnosis and patients seeking help elsewhere. Encouraging first visitors to return to the clinic in case they do not improve might reduce delays.

\section{Conclusion}

This study provides a perspective into the delay of treatment of TB patients in an area of North-Western Tanzania. Three important findings emerged. Firstly, a lack of knowledge about TB signs and symptoms among patients refrains them from visiting a hospital. Secondly, beliefs about witchcraft curses as the cause of diseases hinder people from seeking care at the hospital level. Thirdly, and most alarmingly, other health providers are not co-operating with the hospital.

To reduce the long delay in diagnosing TB patients in rural Tanzania, both the public as well as health providers should be educated and effort should be put into the strengthening of the relationship between other, non-formal and formal, health providers and the hospital.

\section{Limitations of this study}

The findings of this study need to be interpreted in the light of several limitations. Firstly, there may be a recall bias with reference to the duration of symptoms and the timeliness and chronology of health providers consulted, because the participants provided retrospective responses. We tried to minimise the effect of this recall bias by using data from patient files to verify dates and time periods.

Secondly, we cannot rule out the possibility that traditional healers might have been given desirable answers at the time of the interview while, in fact, they are not so willing to refer a possible TB patient to the hospital because of, for example, financial reasons. The sample only included patients who eventually presented themselves at the hospital. The possibility of a selection bias cannot be ruled out, as we did not reach patients who are still treated by other health care providers and might have been there for a very long time. A prospective community-based study would include these patients as well.

Finally, the low specificity of the diagnostic methods (radiography and clinical features) used to detect sputumsmear-negative pulmonary TB could potentially lead to the misdiagnosis of patients. However, the diagnosis of sputum-smear-negative TB cases has been made by experienced clinicians using the recommended diagnostic algorithms [12] to minimise misdiagnosis.

Acknowledgments The authors would like to thank all of the staff of Sumve Hospital, Sumve, Tanzania, for their continuous assistance and support, especially Mary Mmasy, nurse in charge of the tuberculosis ward of Sumve DDH. Furthermore, we thank Dr. H.A.G.H. van Asten and Dr. A.L.M. Lagro-Janssen for critically reviewing an earlier version of this paper.

\section{Conflict of interest None.}

Open Access This article is distributed under the terms of the Creative Commons Attribution Noncommercial License which permits any noncommercial use, distribution, and reproduction in any medium, provided the original author(s) and source are credited.

\section{References}

1. World Health Organization (WHO) Global tuberculosis control: epidemiology, strategy, financing. Geneva, Switzerland: WHO, 2009. WHO/HTM/TB/2009.411.

2. Mfinanga SG, Mutayoba BK, Kahwa A, Kimaro G, Mtandu R, Ngadaya E, Egwaga S, Kitua AY. The magnitude and factors associated with delays in management of smear positive tuberculosis in Dar es Salaam, Tanzania. BMC Health Serv Res. 2008;8:158.

3. Godfrey-Faussett P, Kaunda H, Kamanga J, Van Beers S, Van Cleeff M, Kumwenda-Phiri R, Tihont V. Why do patients with a cough delay seeking care at Lusaka urban health centres? A health systems research approach. Int $\mathrm{J}$ Tuberc Lung Dis. 2002;6:796-805. 
4. Meintjes G, Schoeman H, Morroni C, Wilson D, Maartens G. Patient and provider delay in tuberculosis suspects from communities with a high HIV prevalence in South Africa: a crosssectional study. BMC Infect Dis. 2008;8:72.

5. Bustamante-Montes LP, Escobar-Mesa A, Borja-Aburto VH, Gómez-Muñoz A, Becerra-Posada F. Predictors of death from pulmonary tuberculosis: the case of Veracruz, Mexico. Int $\mathbf{J}$ Tuberc Lung Dis. 2000;4:208-15.

6. Demissie M, Lindtjorn B, Berhane Y. Patient and health service delay in the diagnosis of pulmonary tuberculosis in Ethiopia. BMC Public Health. 2002;2:23.

7. Yimer S, Bjune G, Alene G. Diagnostic and treatment delay among pulmonary tuberculosis patients in Ethiopia: a cross sectional study. BMC Infect Dis. 2005;5:112.

8. Huong NT, Vree M, Duong BD, Khanh VT, Loan VT, Co NV, Borgdorff MW, Cobelens FG. Delays in the diagnosis and treatment of tuberculosis patients in Vietnam: a cross-sectional study. BMC Public Health. 2007;7:110.

9. Sreeramareddy CT, Panduru KV, Menten J, Van den Ende J. Time delays in diagnosis of pulmonary tuberculosis: a systematic review of literature. BMC Infect Dis. 2009;9:91.

10. Wandwalo ER, Mørkve O. Delay in tuberculosis case-finding and treatment in Mwanza, Tanzania. Int $\mathrm{J}$ Tuberc Lung Dis. 2000;4:133-8.

11. Fink A. The survey handbook. 2nd ed. Thousand Oaks: Sage Publications; 2003. p. 167.

12. Ministry of Health and Social Welfare. Manual of the National Tuberculosis and Leprosy Programme in Tanzania, 5th ed. Dar es Salaam: Ministry of Health and Social Welfare; 2006.

13. Storla DG, Yimer S, Bjune GA. A systematic review of delay in the diagnosis and treatment of tuberculosis. BMC Public Health. 2008;8:15.

14. Greeff M, Uys LR, Wantland D, Makoae L, Chirwa M, Dlamini P, Kohi TW, Mullan J, Naidoo JR, Cuca Y, Holzemer WL. Perceived HIV stigma and life satisfaction among persons living with HIV infection in five African countries: a longitudinal study. Int J Nurs Stud. 2010;47:475-86.

15. Shaw JB, Wynn-Williams N. Infectivity of pulmonary tuberculosis in relation to sputum status. Am Rev Tuberc. 1954;69: 724-32.

16. Grzybowski S, Barnett GD, Styblo K. Contacts of cases of active pulmonary tuberculosis. Bull Int Union Tuberc. 1975;50:90-106.

17. Whitehorn J, Ayles H, Godfrey-Faussett P. Extra-pulmonary and smear-negative forms of tuberculosis are associated with treatment delay and hospitalisation. Int $\mathrm{J}$ Tuberc Lung Dis. 2010;14:741-4.

18. Basnet R, Hinderaker SG, Enarson D, Malla P, Mørkve O. Delay in the diagnosis of tuberculosis in Nepal. BMC Public Health. 2009;9:236

19. Ngamvithayapong J, Winkvist A, Diwan V. High AIDS awareness may cause tuberculosis patient delay: results from an HIV epidemic area, Thailand. AIDS. 2000;14:1413-9.

20. Mangesho PE, Shayo E, Makunde WH, Keto GB, Mandara CI, Kamugisha ML, Kilale AM, Ishengoma DR. Community knowledge, attitudes and practices towards tuberculosis and its treatment in Mpwapwa district, central Tanzania. Tanzan Health Res Bull. 2007;9:38-43.

21. Kilale AM, Mushi AK, Lema LA, Kunda J, Makasi CE, Mwaseba D, Range NS, Mfinanga GS. Perceptions of tuberculosis and treatment seeking behaviour in Ilala and Kinondoni Municipalities in Tanzania. Tanzan J Health Res. 2008;10:89-94.

22. Mfinanga SG, Mørkve O, Kazwala RR, Cleaveland S, Sharp JM, Shirima G, Nilsen R. Tribal differences in perception of tuberculosis: a possible role in tuberculosis control in Arusha, Tanzania. Int J Tuberc Lung Dis. 2003;7:933-41.
23. Lorent N, Mugwaneza P, Mugabekazi J, Gasana M, Van Bastelaere S, Clerinx J, Van den Ende J. Risk factors for delay in the diagnosis and treatment of tuberculosis at a referral hospital in Rwanda. Int J Tuberc Lung Dis. 2008;12:392-6.

24. El-Sadr WM, Tsiouris SJ. HIV-associated tuberculosis: diagnostic and treatment challenges. Semin Respir Crit Care Med. 2008;29:525-31.

25. Jellis JE. Human immunodeficiency virus and osteoarticular tuberculosis. Clin Orthop Relat Res. 2002;398:27-31.

26. Lienhardt C, Rowley J, Manneh K, Lahai G, Needham D, Milligan P, McAdam KP. Factors affecting time delay to treatment in a tuberculosis control programme in a sub-Saharan African country: the experience of The Gambia. Int J Tuberc Lung Dis. 2001;5:233-9.

27. Lönnroth K, Thuong LM, Linh PD, Diwan VK. Delay and discontinuity-a survey of TB patients' search of a diagnosis in a diversified health care system. Int J Tuberc Lung Dis. 1999; 3:992-1000.

28. Rojpibulstit M, Kanjanakiritamrong J, Chongsuvivatwong V. Patient and health system delays in the diagnosis of tuberculosis in Southern Thailand after health care reform. Int J Tuberc Lung Dis. 2006; 10:422-8.

29. Kiwuwa MS, Charles K, Harriet MK. Patient and health service delay in pulmonary tuberculosis patients attending a referral hospital: a cross-sectional study. BMC Public Health. 2005; 5:122.

30. Ouédraogo M, Kouanda S, Boncoungou K, Dembélé M, Zoubga ZA, Ouédraogo SM, Coulibaly G. Treatment seeking behaviour of smear-positive tuberculosis patients diagnosed in Burkina Faso. Int J Tuberc Lung Dis. 2006;10:184-7.

31. Lawn SD, Afful B, Acheampong JW. Pulmonary tuberculosis: diagnostic delay in Ghanaian adults. Int $\mathbf{J}$ Tuberc Lung Dis. 1998;2:635-40.

32. Yamasaki-Nakagawa $M$, Ozasa $K$, Yamada N, Osuga $K$, Shimouchi A, Ishikawa N, Bam DS, Mori T. Gender difference in delays to diagnosis and health care seeking behaviour in a rural area of Nepal. Int J Tuberc Lung Dis. 2001;5:24-31.

33. Pronyk RM, Makhubele MB, Hargreaves JR, Tollman SM, Hausler HP. Assessing health seeking behaviour among tuberculosis patients in rural South Africa. Int $\mathbf{J}$ Tuberc Lung Dis. 2001;5:619-27.

34. Sagbakken M, Frich JC, Bjune GA. Perception and management of tuberculosis symptoms in Addis Ababa, Ethiopia. Qual Health Res. 2008;18:1356-66.

35. Brouwer JA, Boeree MJ, Kager P, Varkevisser CM, Harries AD. Traditional healers and pulmonary tuberculosis in Malawi. Int $\mathrm{J}$ Tuberc Lung Dis. 1998;2:231-4.

36. Banerjee A, Harries AD, Nyirenda T, Salaniponi FM. Local perceptions of tuberculosis in a rural district in Malawi. Int $\mathrm{J}$ Tuberc Lung Dis. 2000;4:1047-51.

37. Ngang PN, Ntaganira J, Kalk A, Wolter S, Ecks S. Perceptions and beliefs about cough and tuberculosis and implications for TB control in rural Rwanda. Int $\mathrm{J}$ Tuberc Lung Dis. 2007; 11:1108-13.

38. Steen TW, Mazonde GN. Pulmonary tuberculosis in Kweneng district, Botswana: delays in diagnosis in 212 smear-positive patients. Int J Tuberc Lung Dis. 1998;2:627-34.

39. Liefooghe R, Baliddawa JB, Kipruto EM, Vermeire C, De Munynck AO. From their own perspective. A Kenyan community's perception of tuberculosis. Trop Med Int Health. 1997; 2:809-21.

40. Steen TW, Mazonde GN. Ngaka ya setswana, ngaka ya sekgoa or both? Health seeking behaviour in Batswana with pulmonary tuberculosis. Soc Sci Med. 1999;48:163-72. 